\title{
Reflecting on social psychology and global neo-liberal capitalism
}

\author{
[ B O O K R E VIE W ] \\ McDonald, Matthew \& Wearing, Stephen \\ (2013) Social psychology and theories of \\ consumer culture: A political economy \\ perspective. London: Routledge. ISBN 978- \\ 0-415-81203-0 pbk. Pages viii + 172 .
}

The globalisation of neo-liberal economics in the late twentieth and the early twenty-first centuries has had far-reaching effects on human society and culture. The shift from production to consumption-based economies, the flow of international capital as well as the information technology that makes this possible, and the related outsourcing of production from developed to developing countries have changed how we relate to each other and to ourselves, how our social lives are organised and how we understand our experiences. It therefore seems highly appropriate that social psychology, as a sub-discipline, should have theorised the impact of these global developments on human behaviour and experience. However, in this book, McDonald and Wearing argue that this has generally not been the case. On the contrary, mainstream social psychology has retained a relatively narrow theoretical focus on cognition at the expense of developing relevant, applicable and politically engaged understandings of contemporary social life that assist in addressing and resisting the consequences of the rise of consumerism.

Chapter 1 introduces the authors' orientation towards examining some of the leading areas of research and theory within the field of mainstream social psychology. A central trend of argument throughout is that mainstream

\section{Werner Böhmke}

Department of Psychology

Rhodes University

Grahamstown

w.r.bohmke@ru.ac.za 
social psychological theories fail to provide explanations for social relations, interactions and behaviours that adequately consider the impact of the broader societal, cultural and economic trends underpinning consumer culture in Western societies. The chapter therefore provides a discussion of the ways in which social psychological theorising, through its focus on social cognition, can be argued to support the normalisation of social trends related to increasing consumerism in Western societies. This discussion is followed by an outline of some of the key theoretical concepts relating to consumer culture that can be gainfully employed in broadening social psychology's engagement with the consequences of consumer culture.

The second chapter is devoted to theories of consumer culture. McDonald and Wearing provide an accessible overview of social theorists whose work has influenced the development of theoretical understandings of contemporary Western society, grounding the roots of contemporary consumer culture in the development of capitalist economic modes of production in the late nineteenth and early twentieth centuries and the impact of this on individuals' sense of selfhood and place. The chapter then outlines post-structuralist theories of consumer culture, describing respectively: how the economic shift in Western societies from production to consumption-based economies has led to new forms of governmentality and practices of subjectification; the manner in which the consumption of goods has taken on symbolic meanings associated with social status and self-expression; and how patterns of consumption and their symbolic meanings have come to represent new methods of class differentiation. Thereafter, the chapter reviews social theories of consumer culture analysing changes in social life as a result of the erosion of traditional social institutions; the impact of technology and the way in which consumption is facilitated by information technology; and the reconfiguring of urban and social spaces in ways that normalise and support a consumer lifestyle. The chapter concludes with a discussion of feminist theoretical engagements with consumer culture in Western societies describing the continued gendering of consumption and consumer subjectivities.

Proceeding from this theoretical basis, chapter 3 examines self-identity in consumer culture. The authors outline the predominantly cognitive approach to self-identity adopted by mainstream social psychological theories and illustrate some of the limitations with explaining identity primarily through universal, internal cognitive processes divorced from considerations of broader social structure, economic organisation and cultural context. They argue that to remedy these shortcomings, engagement with how consumer culture shapes individuals' understandings of themselves and others is needed. Several theoretical perspectives on consumer culture are described, tracing how economic shifts in the West, and related increases in ideologies of individualism, competition, market rationality and commodification, 
have fundamentally altered how self-identity is grounded and understood. Consequently, theories of selfhood relying predominantly on cognitive processes are no longer adequate to understand questions of identity; firstly because consumerism has eroded and undermined traditional categories of identity and comparison; and secondly, social comparisons and categorisations are grounded in Western consumer cultures in ways that are intimately related to, if not constituted by, the ideologies of neoliberal consumer capitalism.

Chapter 4 focuses on psychological distress, emotional and behavioural problems. Mainstream social psychological theories have provided explanations for some forms of psychological distress that have been taken up in clinical and abnormal psychology. These explanations deal predominantly with problems of the self and problems of social cognition and their related emotional and behavioural consequences. Typically, these problems are understood as located within the cognitive processes and styles of those experiencing them and therefore the most common interventions have been cognitive-behavioural. However, the authors argue that an understanding of the impact of the ideologies and discursive practices underpinning consumer culture can be useful in recasting several forms of psychological distress as problems related to how contemporary capitalist society produces subjectivities. Furthermore, focusing on internal cognition as the source of psychological distress serves to maintain practices that produce a consuming and self-disciplining subject that perfectly fits a neoliberal and market-oriented vision of society.

Chapter 5 discusses how consumer culture has altered the physical spaces of urban social environments, interactions and relationships. Traditionally, social psychology has envisaged space as a variable impacting on social behaviours, similar to a stimulus in a behaviourist analysis. However, since analyses of consumer culture clearly demonstrate that physical spaces are both constitutive of social interactions, as well as strongly linked to the ideological and political values that underpin consumer culture, such a view is insufficient. The authors argue that under consumer culture in the West, public and social spaces have, firstly, become commodified and commercialised and, secondly, increasingly come under the surveillance of neoliberal governmentality. The simultaneous results of these dynamics have been increased homogenisation, atomisation and instrumentalisation of social life and relationships, as well as increased policing, exclusion and alienation from public space and social participation of those who do not or cannot conform to the ideals of consumer culture. Consequently, the link between place and self-identity that once was the basis of community social relationships has given way to socially impoverished individualism, disconnection and fluid, commodified social identities. 
The final chapter discusses the consequences of globalised, neoliberal consumer capitalism for the environment and highlights the problems of unsustainable overconsumption, pollution, environmental degradation and climate change. The authors stress the need for disciplines concerned with human behaviour and experience to take seriously the macro-economic and political processes that shape our contemporary global society and the deleterious consequences these forces have for the planet. This is pertinent for developing societies, since it is most frequently in such contexts that the effects of a globalised economy, focused on relentless economic expansion, continued increases and excesses in consumption are felt most keenly in the conditions of poverty, precarious labour, the extraction of natural resources and environmental degradation. The authors argue that under these global economic conditions, mainstream social psychology needs to critically engage with the political economy of twenty-first century capitalism. If social psychology is to be useful and relevant, it is time to reflect on the individualistic bias of much of social psychological theory, to engage with the complicity of the epistemological and methodological approaches of social psychology with the ideological foundations of consumer culture, and to take a politically active stance towards resisting the potentially harmful effects of neo-liberal consumer culture on selfidentity, social relationships and the environments in which they occur.

Overall, this is an important work to engage with. The book is accessible and well organised, with the central thesis carried through and developed clearly. The authors argue strongly for a sustained and critical engagement with the contemporary political economy of the early twenty-first century if social psychology is to live up to its potential to engage with and develop effective solutions to the problems of selfhood, alienation and social exclusion that characterise contemporary society. This entails that mainstream social psychology becomes a truly socially-oriented discipline and shifts its focus from internal social cognitions to the broader social, economic, political and cultural phenomena shaping individual experience. One limitation of the book is that the analysis is restricted to Western social contexts. Given the need to consider the impact of globalisation-related changes in society, the book does not really engage with the impact of globalised consumer culture on developing economies and societies, or in non-Western cultural contexts. While it can be argued that precisely due to the globalisation of neoliberal capitalism, consumer culture is fast achieving hegemony; the possibility for localised variations of, or resistances to, consumer culture should not be overlooked. Nor should the different impacts of globalisation in diverse parts of the world be minimised. Consequently, social psychologists in developing, non-Western, or global South contexts may find this book to be less of a description of their current social context than it is an outline of where things may be going and of how psychological theorising needs to articulate a social and political engagement with twenty-first century capitalism. 